\title{
Effects of Diversity on Innovation in Complex Technology Systems and Ownership Structures
}

\author{
Tsutomu Harada ${ }^{1}$ \\ ${ }^{1}$ Graduate School of Business Administration, Kobe University, Japan \\ Correspondence: Tsutomu Harada, Graduate School of Business Administration, Kobe University, Japan. E-mail: \\ harada@people.kobe-u.ac.jp
}

\author{
Received: September 11, $2014 \quad$ Accepted: October 11, $2014 \quad$ Online Published: November 26, 2014 \\ doi:10.5539/jms.v4n4p36 URL: http://dx.doi.org/10.5539/jms.v4n4p36
}

\begin{abstract}
This paper develops models for two types of complex technology systems: symmetric and hub-and-spoke technology systems. It demonstrates that both technology systems are associated with inverted U-shaped relationships between diversity and innovation performance. However, the hub-and-spoke technology system, which incorporates architecture, allows for more diversity in its technology components and architecture, and, hence, for economies of scope. In the second part of this paper, we examine the effects of various ownership structures on optimal diversities of a technology system. In the presence of innovation uncertainty, a trade-off occurs between commitment (a relation-specific investment) and diversity. Thus, vertical integration does not necessarily improve innovation probability more than outsourcing does, because the latter could include more diverse searches that reduce innovation uncertainty. Hence, in contrast to the transaction costs and incomplete contracting literature, the findings presented here indicate that the relative efficiency of these two ownership structures remains undetermined. However, when partial ownership is introduced, the highest innovation probability and diversity can be achieved under this ownership structure.
\end{abstract}

Keywords: diversity, symmetric technology system, hub-and-spoke technology system, inverted U-shape, partial ownership, trade-off between commitment and diversity

\section{Introduction}

Technology cannot be appropriately understood without referring to its context. In particular, a technology is often a component of a larger technology system. For example, an aircraft and its engine design integrate a number of complex subsystems, including electronics, hydraulics, and material technologies. The interaction of these individually complex systems and components imposes considerable technological uncertainty. Consequently, the system integration and design phases are critical to the introduction of innovation in components of technology (Mowery \& Rosenberg, 1991).

However, the highly complex nature of a technology system has been relatively disregarded in economics. In the industrial organization literature, technology has been extensively studied in light of Schumpeter's hypothesis (Cohen \& Levin, 1989). In empirical studies that adopt Schumpeter's hypothesis, relationships between market power and innovation and between scale and innovation have been examined, but innovation has not been disentangled into component levels of technology. In theoretical studies of patent race (Loury, 1979; Lee, 1980; Reinganum, 1989) and endogenous growth (Grossman \& Helpman, 1991; Aghion \& Howitt, 1998), the unit of analysis has been a single technology, and its systemic nature has not been fully incorporated into the analyses.

In the management literature, the highly complex nature of a technology system has been formulated as CoPS (complex product systems), and the characteristics of innovation in CoPS have been comprehensively studied (Miller et al., 1995; Hobday, 1998). While this literature tends to highlight the complex nature of a specific technology system, some related studies place more emphasis on the underlying framework or building blocks behind a complex technology system. In particular, Henderson and Clark (1990) proposed the concept of "architecture" in their attempt to classify various types of innovation from the perspective of system versus component. They claimed that two kinds of knowledge are required for innovation: "component knowledge" and "architectural knowledge". Innovation is classified in terms of its impact on both types of knowledge. Radical (or incremental) innovations have a high (or low) impact on both types of knowledge, while architectural innovations have a high impact on architectural knowledge, but not on component knowledge. That is, 
architectural innovations significantly alter the linkages among component technologies, but the latter remain almost unchanged. Modular innovation has an impact on component knowledge without altering the existing architecture. This argument, therefore, clarifies that innovation in a complex technological system can be understood in terms of the system's own architecture and components.

In a broader perspective, it has recently been argued that the focus of marketing and strategy must be on shaping the ecosystem in which the firm resides, and the firm should shift attention from industry-focused strategic planning towards strategies within and around ecosystems (Iansiti \& Levien, 2004; Teece, 2007; Pierce, 2009; Gulati et al., 2012; Autio \& Thomas, 2014). Ecosystems can be defined as dynamic and purposive networks in which participants co-create value (Adner\& Kapoor, 2010; Lusch et al., 2010). Thus, ecosystem participants co-evolve capabilities around a shared set of technologies and cooperate and compete to support new products, satisfy customer needs, and eventually incorporate the next round of innovation (Moore, 1996).

Although these conceptual frameworks are useful in deepening our understanding of the complex nature of a technology system and its innovations, their economic efficiency is difficult to evaluate without specifying underlying economic incentives and constraints. Once we understand the complex and systemic nature of innovation, questions that subsequently arise are: how does diversity in technology components and architectures affect innovation performance, and what are the effects of various ownership structures on architectures and technology components? The role of diversity in research and development (R\&D) was analyzed by Nelson (1961) in the context of parallel research projects. He found that diversity reduced uncertainty by increasing the probability of success at the cost of duplication in parallel research projects. Thus, there is an optimal degree of diversity that maximizes expected gains from innovation. In the context of a complex technology system, diversity corresponds to the number of technology components and the number of architectures in a given system. This paper examines how these diversities affect innovation performance in technology systems. If the optimal degree of diversity is higher, this implies that the system is conducive to economies of scope. In the opposite case, the system can be regarded as being conducive to more exploitative economies of specialization (Rosenberg, 1976).

The second question, raised above, is relevant to the economic evaluation of a technology system, because establishing technical links with other technology components and architectures often requires relation-specific investment. As the incomplete contracting literature (Grossman \& Hart, 1986; Hart \& Moore, 1990) suggests, this kind of investment generates a holdup problem, which must be remedied through appropriate allocation of ownership. However, our interest does not lie in the relationship between relation-specific investment and ownership. Rather, we are interested in examining the effect of given ownership structures on the innovation performance of a technology system, especially in terms of the diversities of technology components and architectures.

This paper develops simple models of technology systems that consist of technology components. These are related to each other through technical links and the overall structure of the components corresponds to the architecture of the system. We consider two types of technology systems: symmetric and hub-and-spoke systems. In the former, technology components are related symmetrically. In the latter, however, a hub-and-spoke structure is imposed so that a hub technology component governs the overall architecture. In this latter system, all other components are directly related to the hub alone, and any pair of component technologies is intermediated by the hub. This hub-and-spoke system corresponds to modular innovation, as described by Henderson and Clark (1990), because the impact of innovation on architectural knowledge is minimal in this case. We next characterize the optimal diversities of technology components in the two systems and show that a hub-and-spoke system is more conducive to economies of scope than a symmetric system.

Moreover, we analyze how different types of ownership structures within technology systems affect innovation performance. We specifically examine cases of vertical integration, outsourcing, and partial ownership. We consequently demonstrate that partial ownership maximizes innovation probability, and hence, optimal diversities.

The rest of this paper is organized as follows. Section 2 develops models of symmetric and hub-and-spoke technology systems and characterizes their optimal diversities. Section 3 examines the effects of ownership structures on these optimal diversities. Finally, section 4 presents our conclusions.

\section{The Model}

\subsection{Symmetric System}

In this section, we develop a model for asymmetric technology system as follows. Suppose that a firm owns a 
technology system consisting of $n$ technology components, which are linked together. We denote the technical link between the $i$ th and $j$ th technology components by $l_{i j}$. Without loss of generality, we can assume that this link is bidirectional so that $l_{i j}=l_{j i}$ holds. Excluding self-links $l_{i i}$, the number of technical links amounts to $n(n-1)$. Because all of the technology components are symmetrical in terms of their technical links, this technology system can be classified as a symmetric system.

Although this specification of technical links has been disregarded in the literature on the economics of innovation, technical interdependence among technology components is one of the significant characteristics of complex technology systems. As we have already noted, Henderson and Clark (1990) emphasized the importance of product architecture in which technical links among technology components were stipulated. Hugh (1983) classified products into assemblies, component systems, and arrays. According to Hughes (1983), an assembly is usually a mass-produced stand-alone product that performs a single function and does not form part of a wider system. By contrast, a component always performs a role within a larger system, and a system is defined by three characteristics: components, a network structure, and a mechanism of control. Finally, an array is a system of systems, that is, a collection of distinct but interrelated systems, each performing independent tasks but organized to achieve a common goal. An example of an array is an airport consisting of aircrafts, terminals, runways, air traffic controls, and baggage handling systems. Excluding mass-produced stand-alone products, component systems and arrays are characterized by technical links among their technology components. Therefore, the critical importance of incorporating these technical links into a technology system is addressed in our analysis.

Innovation in this type of technology system consists of invention and reintegration. Invention refers to quality improvements or cost reductions of a technology component. Suppose that at the beginning of each period, the firm makes an R\&D investment, and its results are immediately realized so that the firm receives gains from innovation. During the next period, the firm will repeat this R\&D investment in a similar manner if it expects non-negative gains from innovation. We denote the invention probability in this case by $p\left(e_{i}\right)$ where $e_{i}$ is the $\mathrm{R} \& \mathrm{D}$ investment in the $i$ th technology component with $p^{\prime}>0$ and $p^{\prime \prime}<0$. To ensure interior solutions, we assume that $p^{\prime}(0)=\infty$ and $\lim _{e \rightarrow \infty} p(e)=1$. This last condition excludes a scenario in which the invention probability reaches unity.

Once an invention takes place, the improved technology component must be reintegrated into a technology system by reestablishing technical links with all other technology components. To establish a link between two technology components, the firm must bear the coordination cost of $f(<1)$. Without loss of generality, we can assume that this coordination cost is the same among all pairs of technology components.

Suppose that the firm undertakes R\&D investments in all of the technology components of the system. When a technology component succeeds in terms of invention, it has to renew its technical links to all other technology components. Since R\&D technology $p$ is assumed to be the same for all technology components, the firm makes the same amount of R\&D investment in each technology component. Subsequently, according to the law of large numbers, $n p$ technology components are expected to succeed in terms of invention. We denote the gains from innovation of a technology component by $V$, and without loss of generality, $V=1$ can be assumed. The firm maximizes the gains from innovation as

$$
\max _{e} W^{s}=n p\{1-(n-1) f\}-n e .
$$

The first order condition is

$$
\{1-(n-1) f\} p^{\prime}=1
$$

We denote the optimal amount of R\&D investment determined in this equation by $e^{s^{*}}$ and the corresponding innovation probability by $p^{s^{*}} \equiv p\left(e^{s^{*}}\right)$. It is then evident that $e^{s^{*}}$ is negatively dependent on $n$. When the number of technology components increases, R\&D investment is reduced because of higher coordination costs. The total innovation probability (expected number of successful innovations) in this case is represented by $n p^{s^{*}}$.

\subsection{Hub-and-spoke System}

Now, let us introduce a hub-and-spoke structure into a symmetric technology system. Suppose that one technology component, the $h$ th technology component, is selected as a hub and the others correspond to the spokes of the structure (Note 1). A hub-and-spoke structure implies that any technical links between pairs of components are intermediated by the hub. Suppose that the $i$ th component succeeds in terms of invention. The 
corresponding coordination cost amounts to $f$. That is, the $i$ th component, when invention takes place, has to be reintegrated with the hub alone, while the rest of the components remain intact. This is because they have already been integrated with the hub and their technical links are not affected by the $i$ th component. In this hub-and-spoke structure, technical links are represented by $l_{i h}$ for all $i \neq h$. Assuming that the total number of constituent technology components is $n$, not including a hub, the total number of technical links amounts to $n$ instead of $n(n-1)$. For the time being, let us rule out the case of the firm making an R\&D investment in a hub to make a failure comparison between the two technology systems. In this case, the optimal R\&D investment in the components is determined by

$$
\max _{e, n} W^{h}=n p(1-f)-n e
$$

Thus, the first order condition is

$$
(1-f) p^{\prime}=1
$$

In the hub-and-spoke system, the optimal R\&D investment $e^{h^{*}}$ is not dependent on $n$. The expected number of successful innovations is $n e^{h^{*}}$.

PROPOSITION 1: The innovation probability of a hub-and-spoke system is higher than that of a symmetric system so that $e^{h^{*}}>e^{s^{*}}$ holds. Moreover, as $n$ increases, the difference in the innovation probability expands between the two systems.

Thus, economies of scope become more significant in the hub-and-spoke system than in the symmetric system. In other words, the latter takes greater advantage of economies of specialization than the former. As a result, it can be conjectured that the hub-and-spoke technology system is more likely to generate diversity in its components, leading to a higher innovation probability.

\subsection{Diversity in Technology Components}

This conjecture can be confirmed by deriving and comparing optimal diversities of the two systems. For this purpose, we need to endogenize $n$. Suppose that a firm determines the number of components at the inception of the technology system $(t=0)$. From the Le Chatelier principle, the firm determines $n$ to simply maximize

$$
\max _{n} W^{s}=\frac{n}{1-\beta}\left\{p^{s^{*}}\{1-(n-1) f\}-e^{s^{*}}\right\}-\frac{n(n-1)}{2} f,
$$

where $0<\beta<1$ is the discount factor, and the first term on the right-hand side of the equation(RHS) represents the sum of future expected gains from innovation. The second term measures the coordination costs of $n(n-1) / 2$ pairs of technical links at $t=0$. Then, the optimal diversity is given by

$$
n^{s^{*}}=\frac{1}{2}\left[\frac{2 p^{s^{*}}-e^{s^{*}}}{\left\{(1-\beta)+2 p^{s^{*}}\right\} f}+1\right] .
$$

On the other hand, in the case of a hub-and-spoke system, the firm maximizes

$$
\max _{n} W^{h}=\frac{n}{1-\beta}\left\{p^{h^{*}}(1-f)-e^{h^{*}}\right\}-\frac{n(n-1)}{2} f .
$$

We then obtain

$$
n^{h^{*}}=\frac{1}{2}\left[\frac{2\left\{p^{h^{*}}(1-f)-e^{h^{*}}\right\}}{(1-\beta) f}+1\right] .
$$

Comparing (7) and (8), we cannot establish $n^{h^{*}}>n^{s^{*}}$ without further restrictions. However, for higher values of $\beta$, this inequality is always satisfied.

PROPOSITION2: (1) The relation between innovation probability and the diversity of technology components followsan inverted U-shape such that as diversity in the components increases, the innovation probability also increases up to either $n^{s^{*}}$ or $n^{h^{*}}$. After this point, more diversity reduces the innovation probability. 
(2) For higher values of $\beta$, the range of economies of scope (or specialization) is broader (or narrower) in a hub-and-spoke system than in a symmetric system, i.e., $n^{h^{*}}>n^{s^{*}}$.

\subsection{Innovation in the Hub}

While innovation in the $h$ th technology component in a symmetric system makes no significant difference to other technology components, it has a critical effect on a hub-and-spoke system because any changes in the hub necessitate its reintegration with all of the components. This reintegration cost is $n f$. Thus, the expected gains from innovation in a hub technology component are $p-n f-e$, whereas those from a component are $p-f-e$. As long as $n>2, p-n f-e$ is lower than $p-f-e$. Therefore, it is more efficient for a firm to make R\&D investments in constituent components.

PROPOSITION 3: In the case of a hub-and-spoke system, a firm has less incentive to make an R\&D investment in a hub technology component.

In particular, when a firm is severely bound by budget constraints, limited $R \& D$ resources are invested solely in non-hub technology components. In this case, it is optimal not to make an R\&D investment in a hub technology component.

This result could be interpreted as a generalization of the productivity dilemma thesis proposed by Abernathy (1978). Based upon his observation of the US automobile industry, Abernathy (1978) argued that industrial competition is driven by the staged evolution of products and production processes. In the early fluid stage of the industry's development, since customers' requirements are not well understood, competition involves a high level of experimentation and a rapid turnover of product designs. The production processes appropriate to this stage are small-scale, flexible, and labor-intensive, which are conducive to rapid production innovation. At some point, however, certain dimensions of product design become standardized. This is referred to as the emergence of a "dominant design." Large-scale capital investments are made and process innovation is facilitated. However, the development of production processes makes it extremely costly to generate and adopt product innovations that significantly modify the current dominant design. As a result, more process innovation leads to less product innovation, a relation that corresponds to the "productivity dilemma."

In the context of the model developed in this paper, the productivity dilemma can be applied to the case of a hub-and-spoke technology system wherein once a hub technology component is determined, subsequent developments in the technology components make it costly to change the hub technology. In particular, large-scale capital investment implies that the coordination cost of an updated hub technology component, $n f$, is sufficiently high. Therefore, the firm has less incentive to make an R\&D investment in a hub technology component.

In this respect, it should be noted that hub technology components differ from core technologies. In core technologies, innovations are more likely to be sustained over time because they generate higher gains (Harada, 2014). By contrast, according to proposition 3 , hubs are not frequently updated. Thus, hubs should be interpreted as corresponding to the architecture rather than to the core. This is because architecture is defined as the underlying framework of constituent components. Parallel concepts include natural trajectories (Nelson \& Winter, 1977), technological trajectories (Dosi, 1982) and technological guideposts (Sahal, 1985), all of which can be defined based on underlying technological paradigms (Dosi, 1982). Dosi (1982) broadly defined a technological paradigm as an outlook, a set of procedures, and a definition of the relevant problems, and of the specific knowledge related to the solution. A technological trajectory is defined as the direction of advances within a technological paradigm. Thus, both the architecture and the technological paradigm should not be frequently altered because they are the building blocks upon which innovation proceeds. Our model of a hub-and-spoke system can be viewed as the formalization of the architecture and technological paradigm in a technology system.

\subsection{Diversity in Hubs}

Although a firm has less incentive to make an R\&D investment in a hub technology component, it could improve the total innovation probability by incorporating diverse hub technology components. As long as each hub has already established technical links to its technology components, integration of several hubs does not create large coordination costs. Suppose that $m$ hubs exist and that each hub has $n$ technology components. If they are integrated, innovation in a technology component incurs the coordination cost, $m f$. That is, the new innovation has to be reintegrated only with $m$ hubs, leaving other constituent technology components unaffected. The firm can then determine the optimal diversity in hub technology components to maximize the following: 


$$
\max _{m} W^{m h}=m\left[n\left\{p^{h^{*}}(1-f)-e^{h^{*}}\right\}\right]-\frac{m(m-1)}{2} F,
$$

where $F$ denotes the coordination cost of integrating two hub technology components. Since $m$ hub technology components exist, their integration incurs the cost, $m(m-1) F / 2$. The optimal diversity in hub technology components is given by

$$
m^{*}=\frac{n\left\{p^{h^{*}}(1-f)-e^{h^{*}}\right\}+1 / 2}{F} .
$$

PROPOSITION 4: The relationship between innovation probability and diversity in hubs follows an inverted $U$-shape so that as diversity in hubs increases, the innovation probability also increases up to a peak point. After that point, more diversity reduces the innovation probability.

Both propositions 2 and 4 suggest that the diversity effects on innovation probability follow an inverted U-shape. First, when the diversity level remains low, economies of scope or the diversity effect dominate. However, coordination costs gradually increase and eventually outweigh the diversity effect when the diversity level rises above the optimal level. Economies of specialization subsequently prevail. In other words, the trade-off between diversity and commitment matters in relation to the effects of diversity on innovation probability.

\section{Ownership Structure}

In this section, we examine how different ownership structures affect innovation probability in technology systems. An examination of the ownership structure in these technology systems is particularly important because relation-specific investment is usually required when establishing technical links. These links lose their significance as soon as technology components are detached from the connected hubs. Suppose that a hub is owned by a firm, and the components may be owned either by the firm or by specialized suppliers. In this scenario, three types of ownership structure could emerge: (1) outsourcing; (2) vertical integration; and (3) partial ownership. Of these structures, partial ownership is relatively new within the literature on relational contracts. As we will see, this is a hybrid form of vertical integration and outsourcing in which complete ownership is divided between the firm and a specialized supplier.

\subsection{Outsourcing}

First, let us consider outsourcing. Suppose that R\&D investment is nonverifiable, but that invention is verifiable. Inan outsourcing ownership structure, without loss of generality, the gains from innovation can be assumed to be equally divided between the firm and a specialized supplier. This is because invention generates quasi-rent relevant only to the hub owned by the firm, and the Nash bargaining solution leads to an equal division between the two parties. We can assume that a specialized supplier is required to bear the costs of anR\&D investment and technical link to the hub. Moreover, before a successful supplier actually provides an invented component to the firm, $g$ potential suppliers are assumed to undertake R\&D for invention. The R\&D investment by a supplier is then determined by

$$
\max _{e} W^{O}=\frac{1}{2}(1-p)^{g-1} p(1-f)-e .
$$

$(1-p)^{g-1} p$ on the RHS measures the probability that this supplier alone succeeds, while other competitors do not succeed in terms of invention. Conditional on this event, the supplier gains the profits resulting from the invention. Thus, competition reduces the expected gains from invention and the corresponding R\&D investment. We denote the optimal R\&D investment in (11) by $p^{O}$ where the superscript ${ }^{O}$ indicates outsourcing. In this case, the expected gains from innovation for the firm are

$$
V^{O}=\frac{1}{2}\left\{1-\left(1-p^{o}\right)^{g}\right\}(1-f),
$$

where $1-\left(1-p^{o}\right)^{g}$ on the RHS represents the probability that at least one supplier succeeds in terms of invention.

\subsection{Vertical Integration}

Inthe case of a vertical integration ownership structure, a firm makes an $R \& D$ investment and owns the invention. Obviously, this case generates the first best solution. The firm maximizes 


$$
V^{V I} \equiv \max _{e} W^{*}=p(1-f)-e,
$$

where $V^{V I}$ denotes the expected gains from innovation in a vertical integration structure. Comparing (11) and (13), we obtain $e^{*}>e^{O}$ where the superscript * indicates the equilibria of the first best solution. Thus, relation-specific investment results in a holdup problem, which can be remedied through vertical integration. This is a standard result in incomplete contracting theory and transaction cost economics.

However, this result does not necessarily lead to the relative efficiency of vertical integration over outsourcing, because the overall innovation probability must also be evaluated in this model. The innovation probabilities of outsourcing and vertical integration are $1-(1-p)^{g}$ and $p$, respectively. If $g$ is sufficiently large, the innovation probability of a vertical integration structure surpasses that of an outsourcing structure. In this case, outsourcing is more efficient than vertical integration, even if it introduces a holdup problem. As no uncertainty is involved in a standard model of the holdup problem in the $t$ literature, this result does not arise. By contrast, the model developed in this paper incorporates the uncertainty of R\&D. Thus, the roles not only of commitment, but also of diversity in reducing uncertainty are critical in determining relative efficiency. In other words, a trade-off occurs between commitment and diversity in this model.

Moreover, in reality, even after vertical integration, an owner cannot manage and make decisions concerning all R\&D investments. If an owner is in the top management, some decision rights are delegated to subordinates or subunits, and nonverifiability of R\&D investment once again results in agency costs. In this case, the owner cannot simply pay for $e$ in exchange for his or her subordinate's effort. Therefore, unless the firm has a single owner, vertical integration does not necessarily replicate first best solutions.

Suppose that a firm can make payment contingent on whether or not a subordinate succeeds in terms of invention. This contract is feasible as long as the parties responsible for enforcing contracts can verify the realization of invention. Without loss of generality, we can assume that this payment entails equal division of the gains from invention. Then, the R\&D investment by subordinates is precisely determined by (11) when $g$ employees undertake R\&D. The expected gains from innovation for the firm are

$$
V^{V I}=V^{O}
$$

Accordingly, vertical integration does not resolve the holdup problem unless the owner personally makes an R\&D investment.

\subsection{Partial Ownership}

As long as R\&D investment is nonverifiable and executed by non-owners, simple vertical integration does not resolve the holdup problem. What is required, then, is a division of ownership and joint investment in R\&D by both an owner and the employees. A mere division of the gains from innovation as a result of partial ownership is not significantly different from outsourcing. What differentiates partial ownership from outsourcing and vertical integration is that in the former case, the owner also makes an R\&D investment. Evidently, even in outsourcing, the firm may, in special cases, make some complementary R\&D investment. However, according to our classification, such cases should be categorized under partial ownership because the firm has ownership over the results of its own R\&D investment.

Suppose that the innovation probability is now denoted by $p\left(e^{o w n r}, e^{\text {empl }}\right)$ which is strictly increasing and concave in $e^{o w n r}$ and $e^{e m p l}$. In this case, $e^{o w n r}$ and $e^{\text {empl }}$ denote the R\&D investment by the owner and employee (potential supplier), respectively. To simplify the analysis, we assume that

$$
p\left(e^{o w n r}, e^{e m p l}\right)=p\left(e^{o w n r}\right)+p\left(e^{e m p l}\right),
$$

where $p(e)$ on the RHS is the same as the innovation probability function above. However, we further assume that $p\left(e^{\text {ownr }}, e^{\text {empl }}\right)=1$ is never achieved in (15). The costs of R\&D investment are now denoted by $e^{j}(\alpha)$ ( $j=$ ownr, empl) with $e^{\prime}(\alpha)>0$. We next examine two cases involving this cost function: (a) $e(\alpha)=\alpha e$ (constant returns); and (b) $e(\alpha)<\alpha e$ (increasing returns). We can rule out (b), because outsourcing and vertical integration are more efficient than partial ownership in this case. In (b), we can assume that some cost advantage arises as a result of learning effects such as access to a common knowledge base, economies of specialization, and technology spillovers. For example, when outsourcing, a firm cannot acquire access to the knowledge base of potential suppliers before the invention is developed. Alternatively, division of labor in innovation between the owner and suppliers generates economies of specialization such that R\&D costs consequently decrease. 
Suppose that the owner (firm) and a successful employee (supplier) have $\alpha$ and $1-\alpha$ shares of ownership on innovation where $0 \leq \alpha \leq 1$. Let us assume that there are $g$ potential suppliers. Then, the R\&D investment is determined by

$$
\begin{gathered}
\max _{e^{o w n r}, \alpha} \alpha\left\{1-\left(1-p\left(e^{\text {ownr }}, e^{\text {empl }}\right)\right)^{g}\right\}-e^{\text {ownr }}(\alpha) . \\
\max _{e^{a m p l}}(1-\alpha)\left(1-p\left(e^{\text {ownr }}, e^{\text {empl }}\right)\right)^{g-1} p\left(e^{\text {ownr }}, e^{\text {empl }}\right)-e^{\text {empl }}(1-\alpha) .
\end{gathered}
$$

Note that in (16), the owner (firm) is also assumed to determine the optimal share of ownership on innovation. According to (17), if $\alpha=1$, no potential suppliers make an R\&D investment. This case corresponds to vertical integration. When $\alpha=1 / 2$, the result appears similar to that of outsourcing described above. However, since the firm also makes an R\&D investment in this case, the resulting innovation probability is higher than that for outsourcing. Therefore, partial ownership should be compared with vertical integration in terms of innovation probability.

We can then obtain the following result:

PROPOSITION 5:There exist some values of $\alpha^{*}$ where $0<\alpha^{*}<1$ for which the innovation probability is higher than for vertical integration and outsourcing.

Proof: If $e(\alpha)=\alpha e$, then R\&D investment is determined independently of $\alpha$. However, in the case of $\alpha=1$, potential suppliers never make any R\&D investment. Similarly, if $\alpha=0$, the firm does not make any R\&D investment. Therefore, innovation probability becomes higher for any value of $0<\alpha<1$. Next, consider the case of $e(\alpha)<\alpha e$. Suppose that $\alpha=1$. Then, potential suppliers do not make any R\&D investment. If we reduce $\alpha$ by a small amount, $\varepsilon$, (16) increases according to the assumption that $e(\alpha)<\alpha e$, even without any $\mathrm{R} \& \mathrm{D}$ investment being made by potential suppliers. Thus, the optimal $\alpha$ should be less than unity and the resulting innovation probability is higher than $\alpha=1$. A similar argument can be applied to the case of $\alpha=0$. Q.E.D.

Of the three alternative ownership structures, partial ownership achieves the highest innovation probability because it is an optimal mixture of vertical integration and outsourcing. On the one hand, vertical integration facilitates relation-specific (R\&D) investment if the investment is made by the owner. On the other hand, outsourcing allows for the diversity that reduces uncertainty regarding innovation. Partial ownership thus takes advantage of both commitment and diversity.

What, then, are the effects of ownership structure on the diversities $n$ and $m$ ? Evidently, these effects depend on the magnitude of the expected gains from innovation. Higher expected gains from innovation lead to increased diversities as (5), (7), and (9) clearly indicate. Because the relative performance of vertical integration and outsourcing in terms of innovation probability remains ambiguous, we cannot ascertain which contracting mode generates higher diversities. However, proposition 5 clearly indicates that partial ownership achieves the highest diversities in $n$ and $m$ compared with vertical integration and outsourcing.

\subsection{Empirical Relevance}

Although vertical integration and outsourcing are widely observed, partial ownership may be less familiar and not well understood in general. However, we can identify some cases of partial ownership. For example, in the Japanese automobile industry, automobile assemblers extensively use partial equity stakes in relation to their key suppliers. In their sample, Ahmadjian and Oxley (2005) showed that on average, Japanese automobile assemblers hold $20 \%$ of the shares of their suppliers, and that one third of the equity ties involved stakes of less than $5 \%$. Dyer (2009) specifically noted that Toyota owns roughly $28 \%$ of the shares of its top 10 major supply partners.

While both Ahmadjian and Oxley (2005) and Dyer (2009) have argued that the use of partial equity stakes can be regarded as credible commitments (Williamson, 1985), the model developed in this paper suggests that the extensive use of partial equity stakes represents partial ownership in which the gains from innovation are divided between an assembler and suppliers who jointly make an R\&D investment.

For example, the development of new Toyota parts is usually undertaken by Toyota if the company already possesses the relevant knowledge and capability. However, if new parts require technologies beyond its capacity, Toyota seeks partners, some of which are partially owned by Toyota, based on their performance track record, and gives them the first opportunity to undertake the required development (Dyer, 2009). In this case, joint R\&D research is launched, and once a new part is successfully developed, Toyota decides whether it will be procured internally or outsourced. $R \& D$ investment by Toyota plays a critical role in the selection of suppliers, because it provides the capacity to evaluate the potential performance of selected suppliers (Note 2). 
Thus, partial ownership in the Japanese automobile industry is widely observed in the form of equity stakes in suppliers and joint R\&D for the development of new parts. The findings presented in this paper show that partial ownership maximizes innovation probability and the diversities in architectures and constituent technology components (Note 3).

\section{Conclusions}

In this paper, we have developed simple models of technology systems that consist of multiple technology components. We have examined optimal diversities in architectures and components, and explored how ownership structures affect these optimal diversities. Our findings have shown that inverted-U relationships exist between diversity and innovation performance for both the architectures and components of complex technology systems. Whereas benefits from economies of scope are initially observed, the gradual domination of economies of specialization is evident. In particular, a hub-and-spoke system that imposes an architectural structure on a technology system leads to higher diversity and innovation performance. One of the implications of this result is that diversity should be encouraged within architectural technology systems in terms of both architectures and constituent components, which may result in a very complex system such as a CoPS. By contrast, a symmetric system should be simplified with less diversity in its components.

In addition to the diversity observed in the system's architecture and constituent components, another type of diversity, $g$, plays a critical role in improving innovation probability. While vertical integration generally tends to reduce this type of diversity, outsourcing allows for more R\&D activities to be undertaken by potential suppliers. As Nelson (1961) has shown, this type of diversity evidently reduces innovation uncertainty, and hence, increases the expected gains from innovation.

Thus, in the context under investigation, a trade-off occurs between commitment and diversity in a make-or-buy decision problem. That is, whereas vertical integration facilitates commitment in terms of relation-specific investment, it is simultaneously associated with less diversity in its reduction of innovation uncertainty. This trade-off has been disregarded in the literature on incomplete contracting and transaction cost because of the focus on a static holdup problem. However, once innovation uncertainty is incorporated into the analysis, this trade-off inevitably arises. Consequently, the relative efficiency of vertical integration over outsourcing becomes indeterminate. When diversity in innovation trials is sufficiently high in outsourcing, the resulting innovation probability would be higher than that of vertical integration. When a firm with a vertical integration ownership structure generates diversity through delegation, underinvestment associated with the hold-up problem once again results. Efficiency in this structure then becomes equivalent to that in an outsourcing structure with the same value of $g$.

This indeterminacy partially disappears when partial ownership is introduced into this evaluation. Our analysis has revealed that partial ownership achieves higher innovation probability and diversity than both vertical integration and outsourcing. This is because a trade-off exists between commitment and diversity and partial ownership takes advantage of both vertical integration and outsourcing. Therefore, the combination of partial ownership with an architectural technology system generates the highest dynamic efficiency in our model, with the highest diversities in architectures and components.

Although various technology systems have been intensively studied within the management literature, formal analysis of these systems has been carried out within relatively few studies. This paper has attempted to undertake an economic analysis of technology systems in terms of diversity in the architectures and components of complex technology systems. We hope it stimulates further economic analysis of technology systems in the future.

\section{Acknowledgements}

I would like to thank seminar participants at Kyoto University, Osaka University, and Kobe University for very useful comments and suggestions. This work was supported by JSPS KAKENHI Grant Number 26380506. Any errors in this paper are the sole responsibility of the author.

\section{References}

Abernathy, W. J. (1978). The Productivity Dilemma: Roadblock to Innovation in the Automobile Industry. Baltimore: John Hopkins University.

Adner, R., \& Kapoor, R. (2010). Value creation in innovation ecosystems: how the structure of technological interdependence affects firm performance in new technology generations. Strategic Management Journal, 31, 306-333. http://dx.doi.org/10.1002/smj.821

Aghion, P., \& Howitt, P. W. (1998). Endogenous Growth Theory. Cambridge, MA: MIT Press. 
Ahmadjian, C., \& Oxley, J. (2006). Using hostages to support exchange: dependence balancing and partial equity stakes in Japanese automotive supply relationships. Journal of Law, Economics, \& Organization, 22, 213-233. http://dx.doi.org/10.1093/jleo/ewj003

Autio, E., \& Thomas, L. D. W. (2014). Innovation ecosystems: implications for innovation management? In M. Dodgson, D. M. Gann, \& N. Phillips (Eds.), The Oxford Handbook of Innovation Management. Oxford: Oxford University Press.

Cohen, W. M., \& Levin, R. C. (1989). Empirical studies of innovation and market structure. In R. Schmalensee \& R. D. Willig (Eds.), Handbook of Industrial Organization. Amsterdam: Elsevier Science Publishers B.V.

Dosi, G. (1982). Technological paradigms and technological trajectories. Research Policy, 11, 147-162.

Dyer, J. (2009). The Value of Trust in Business Networks. San Francisco: Jossey-Bass.

Grossman, G. M., \& Helpman, E. (1991). Innovation and Growth in the Global Economy. Cambridge, MA: MIT Press.

Grossman, S. J., \& Hart, O. D. (1986). The costs and benefits of ownership: a theory of vertical and lateral integration. Journal of Political Economy, 94, 691-719. http://dx.doi.org/10.1086/261404

Gulati, R., Puranam, P., \&Tushman, M. (2012). Meta-organization design: rethinking design in interorganizational and community contexts. Strategic Management Journal, 33, 571-586. http://dx.doi.org/10.1002/smj.1975

Harada, T. (2014). Focusing device as innovation mechanism and cluster growth. Economics of Innovation and New Technology, 23, 49-62. http://dx.doi.org/ 10.1080/10438599.2013.806407

Hart, O., \& Moore, J. (1990). Property rights and the nature of the firm. Journal of Political Economy, 98, 1119-1158. http://dx.doi.org/10.1086/261729

Henderson, R. M., \& Clark, K. B. (1990). Architectural innovation: the reconfiguration of existing product technologies and the failure of established firms. Administrative Science Quarterly, 35, 9-30. http://dx.doi.org/10.2307/2393549

Hobday, M. (1998). Product complexity, innovation and industrial organisation. Research Policy, 26, 689-710. http://dx.doi.org/10.1016/S0048-7333(97)00044-9

Hughes, T. P. (1983). Networks of Power: Electrification in Western Society, 1880-1930. Baltimore: The Johns Hopkins University Press.

Iansiti, M., \& Levien, R. (2004). Strategy as ecology. Harvard Business Review, 82, 68-78. http://hbr.org/2004/03/strategy-as-ecology/ar/1

Lee, T. (1980). Market structure and innovation: a reformulation. Quarterly Journal of Economics, 94, 429-436. http://dx.doi.org/10.2307/1884551

Loury, G. C. (1979). Market structure and innovation. Quarterly Journal of Economics, 93, 395-410. http://dx.doi.org/10.2307/1883165

Lusch, R. F., Vargo, S. L., \& Tanniru, M. (2010). Service, value networks and learning. Journal of the Academy of Marketing Science, 38, 19-31. http://dx.doi.org/10.1007/s11747-008-0131-z

Miller, R., Hobday, M., Leroux-Demers, T., \& Olleros, X. (1995). Innovation in complex systems industries: the case of flight simulation. Industrial and Corporate Change, 4, 363-400. http://dx.doi.org/10.1093/icc/4.2.363

Moore, J. F. (1996). The Death of Competition: Leadership and Strategy in the Age of Business Ecosystems. New York: Harper Business.

Mowery, D. C., \& Rosenberg, N. (1991). Technology and the Pursuit of Economic Growth. Cambridge: Cambridge University Press.

Nelson, R. R. (1961). Uncertainty, learning, and the economics of parallel research and development efforts. Review of Economics and Statistics, 43, 351-364.

Nelson, R. R., \& Winter, S. G. (1977). In search of useful theory of innovation. Research Policy, 6, 36-76. http://dx.doi.org/10.1016/0048-7333(77)90029-4

Pierce, L. (2009). Big losses in ecosystem niches: how core firm decisions drive complementary product shakeouts. Strategic Management Journal, 30, 323-347. http://dx.doi.org/10.1002/smj.736 
Reinganum, J. F. (1989). The timing of innovation: research, development, and diffusion. In R. Schmalensee \& R. D. Willig (Eds.), Handbook of Industrial Organization. Amsterdam: Elsevier Science Publishers B.V.

Rosenberg, N. (1976). Perspectives on Technology.Cambridge: Cambridge University Press.

Rosenberg, N. (1990). Why do firms do basic research (with their own money)? Research Policy, 19, 165-174. http://dx.doi.org/10.1016/0048-7333(90)90046-9

Sahal, D. (1985). Technological guideposts and innovation avenues. Research Policy, 14, 61-82. http://dx.doi.org/10.1016/0048-7333(85)90015-0

Teece, D. J. (2007). Explicating dynamic capabilities: the nature and microfoundations of (sustainable) enterprise performance. Strategic Management Journal, 28, 1319-1350. http://dx.doi.org/10.1002/smj.640

Williamson, O. E. (1985). The Economic Institutions of Capitalism. New York: Free Press.

\section{Notes}

Note 1. Since "spokes" correspond to the links connected with a hub rather than to the nodes, we do not refer to technology components as "spokes". Instead, we simply call them "components" in this paper.

Note 2. In this respect, Rosenberg (1990) argued that a firm performs basic research to monitor and evaluate research being conducted externally. Thus, although Toyota may not undertake the production of a new auto part, it undertakes R\&D activity to monitor and evaluate the capacity of its suppliers.

Note 3. In the automobile industry, the architecture seems to be fixed as the internal-combustion gasoline engine. However, recent movements toward fuel-cell vehicles and electric vehicles represent expanding diversity in the architecture itself.

\section{Copyrights}

Copyright for this article is retained by the author(s), with first publication rights granted to the journal.

This is an open-access article distributed under the terms and conditions of the Creative Commons Attribution license (http://creativecommons.org/licenses/by/3.0/). 